\title{
Triple therapy (ICS/LABA/LAMA) in COPD: thinking out of the box
}

\author{
Lowie E.G.W. Vanfleteren (1), Anders Ullman, Anita Nordenson, \\ Anders Andersson, Kristina Andelid and Leonardo M. Fabbri (B)
}

COPD center, Institute of Medicine, Sahlgrenska University Hospital, University of Gothenburg, Gothenburg, Sweden.

Correspondence: Lowie E.G.W. Vanfleteren, COPD Center, Institute of Medicine, Sahlgrenska University Hospital, University of Gothenburg, Gothenburg, Sweden. E-mail: lowie.vanfleterenavgregion.se

@ERSpublications

Triple inhaler therapy in COPD might in some real-life situations be useful outside of the strict indications reported by the registration agencies, but at the same time in some other situations it could be better avoided, even when recommended http://ow.ly/CbOe30njXV2

Cite this article as: Vanfleteren LEGW, Ullman A, Nordenson A et al. Triple therapy (ICS/LABA/ LAMA) in COPD: thinking out of the box. ERJ Open Res 2019; 5: 00185-2018 [https://doi.org/ 10.1183/23120541.00185-2018].

A current hot topic in COPD is that two "fixed triple" combinations of an inhaled corticosteroid (ICS), a long-acting $\beta_{2}$-agonist (LABA) and a long-acting muscarinic antagonist (LAMA) in a single inhaler have become available for patients with COPD, and a third triple therapy is in advanced development with the first large randomised clinical trial (RCT) recently published in Lancet Respiratory Medicine [1]. The triple therapies available in a single inhaler are: beclomethasone-dipropionate/formoterol/glycopyrronium (BDP/ FF/G); fluticasone-furoate/vilanterol/umeclidinium (FLF/VI/UMEC); and budesonide/glycopyrronium/ formoterol $(\mathrm{B} / \mathrm{G} / \mathrm{F})$.

Whether triple therapy in a single inhaler outperforms the three individual components given in separate inhalers is unknown. In fact, there is only one study where the triple therapy in a single inhaler was compared to triple therapy in separate inhalers, but the LAMA was different with glycopyrronium in the former $(\mathrm{BDP} / \mathrm{FF} / \mathrm{G})$ and tiotropium in the latter. The two triple therapies were equally effective, and both superior to tiotropium alone [2].

For the time being, the additional benefit of a fixed triple LABA/LAMA/ICS combination is related to convenience for the patient, and possibly improved compliance. However, we may speculate that the simultaneous delivery to the target organ of three agents with different mechanisms of action may improve positive interactions between them. In addition, triple therapy might improve activity levels through bronchodilation or reduced breathlessness, and thereby improve respiratory muscle strength and impact upon disease progression.

FLF/VI/UMEC is approved in the European Union as a maintenance treatment in adult patients with moderate-to-severe COPD who are not adequately treated by a combination of an ICS/LABA or LABA/ LAMA, whereas BDP/FF/G is approved only for patients not controlled by LABA/ICS combination (the approval in addition to LABA/LAMA is pending). In the USA, only FLF/VI/UMEC is approved, both for the long-term, maintenance treatment of airflow obstruction in patients with severe COPD and to reduce exacerbations of COPD in patients with a history of exacerbations. These slightly different indications have in common that triple therapy is recommended for patients not adequately controlled by existing inhaled combination therapies. Neither the European Medicines Agency (EMA) nor the US Food and Drug Administration (FDA) make a distinction between initiation of therapy in untreated newly diagnosed

Received: Oct 162018 | Accepted after revision: Dec 192018

Copyright $\odot$ ERS 2019. This article is open access and distributed under the terms of the Creative Commons Attribution Non-Commercial Licence 4.0 
patients, versus use of triple therapy in already treated patients, as both assume triple therapy is a step-up. The position proposed by the 2019 Global Initiative for Chronic Obstructive Lung Disease (GOLD) strategy document [3] recommends triple therapy only as a step-up from LAMA/LABA or ICS/LABA in patients whose disease is not adequately controlled by one of these two combinations. While the positioning of the triple therapy recommended by GOLD, and by the FDA and EMA, is straightforward, the published evidence on which these recommendations are based suggest that there are other conditions in which triple might be considered or not recommended.

Several reviews and editorials have been already published on triple therapy in COPD [4-9], but none of them address the issues related to the possible use of triple therapy in real life, possibly outside of the strict indications reported by the registration agencies, or when triple therapy should not be considered at all even when recommended.

As members of a specialised hospital-based "COPD Centre", we thought that a short commentary "thinking outside the box" on the potential practical use (or non-use) of triple therapy might provide a stimulating tool for discussion in the pulmonary community.

\section{Possible use of triple therapy outside of the recommendations}

1) While the strongest part of the evidence for triple therapy is based on results on exacerbations, in individual patients the change of treatment is most frequently based on symptoms. Indeed, the SPIROMICS study showed that in subjects with GOLD stage 1 and 2 COPD, the prevalence of the use of ICS and bronchodilators was $22 \%$ and $39 \%$ in those with low symptoms (COPD Assessment Test (CAT) $<10$ ) and $46 \%$ and $67 \%$ in those with high symptoms (CAT >10) [10]. It has been shown in real-life analysis that $32 \%$ of all patients with a diagnosis of COPD in primary care end up with triple therapy within 1 year of diagnosis [11]. This inevitable drift to triple therapy is almost invariably due to a limited effect of any regular treatment for COPD (LABA, LAMA, LABA/LAMA, LABA/ICS and even triple therapy) on both symptoms and use of rescue medication. Thus, individual patients are highly likely to be overtreated in order to increase such a limited effect. This suggests that a trial with triple therapy will be almost invariably be tried "ex juvantibus" in every patient even without a risk of exacerbation, who remain highly symptomatic on LAMA, LABA/LAMA or LABA/ICS. In this case, a step-down should be strongly recommended if after 1-3 months patients do not report improvement of symptoms.

2) Patients with a rapid decline in lung function. Previous large studies have clearly shown that ICS alone does not alter lung function decline in patients with COPD [12-15]. However, there is increasing amount of more recent literature that supports a role for ICS combined with bronchodilators suggesting an effect on lung function decline. In a post hoc analysis of UPLIFT [16], a modest reduction in decline was seen in patients on LAMA (but of note a high proportion of included subjects were on ICS [17]). In a post hoc analysis of TORCH [12], ICS combined with LABA was shown to slow down the decline in lung function [17]. The ICS/LABA effect has been confirmed in a recent large long-term prospective study conducted in moderate COPD patients with increased cardiovascular risk. Indeed, even if the study failed in showing a significant effect on survival (primary outcome), it demonstrated a decrease of lung function decline with no increase of pneumonia in patients treated with LABA/ICS versus patients treated with LABA alone [18, 19]. In addition, the WISDOM study showed no increase in exacerbation risk but a significant decline in lung function when ICS was withdrawn in COPD patients treated with triple LABA/LAMA/ICS [20].

In a post hoc analysis of the FULFIL study, only $25 \%$ of those on FF/UMEC/VI, compared with $56 \%$ of those on budesonide/formoterol (BUD/FOR), experienced a clinical meaningful decline in lung function of $>100 \mathrm{~mL}$ in the intention to treat population during the 26 weeks study period, suggesting that the triple FF/UMEC/VI therapy may significantly reduce the risk of clinically important deterioration versus twice daily BUD/FOR with a five-fold longer period without deterioration [21]. Finally, it seems that an accelerated decline in lung function is particularly the case in those COPD patients with self-reported late-onset asthma [22]. In the light of the above evidence retrieved from the literature, we suggest considering triple therapy COPD patients who present with a significant lung function decline.

3) All six studies supporting triple therapy included COPD patients with a history of asthma, even if they excluded subjects with active asthma [1,2, 23-26]. We believe that all symptomatic COPD patients with a history of asthma and/or current asthma, or concomitant traits characteristic for the presence of asthma as described earlier [27], should be considered for triple therapy if not adequately controlled by LABA/ICS and in any case should not be treated with long-acting bronchodilators without ICS. In individual cases, even higher doses of ICS then commonly used in COPD might be appropriate.

4) Concerning patients with asthma, the most recent 2018 Global Initiative for Asthma strategy document recommends adding tiotropium to patients with asthma who have airflow limitation even when treated with LABA/ICS combination [28]. None of the five studies with a triple therapy combination in a single 
inhaler included tiotropium; however, VESTBO et al. [2] showed equivalence between BDP/FF/G and tiotropium plus $\mathrm{BDP} / \mathrm{FF}$ in a separate inhaler in COPD, thus it is reasonable to predict that triple combination in a single inhaler will be frequently used in symptomatic asthma patients with persistent airflow limitation who would require additional bronchodilatation with a LAMA. RCTs testing triple therapy in severe asthma are ongoing, and the results will be available soon (e.g. the TRIGGER Study, ClinicalTrials.gov identifier: NCT02676089).

5) Most of the evidence collected, to date, with triple therapy in a single inhaler included patients with moderate-to-very severe airflow limitation with increased risk of exacerbations suggested by at least one (not two) moderate exacerbations per year while receiving LAMA, LABA/LAMA or LABA/ICS. Thus, we believe that these criteria should be used with confidence in clinical practice, maybe limiting to one rather than two the number of exacerbations in the previous year as a risk factor for future exacerbations to be used for prescription of regular triple therapy [29]. Indeed, studies on large cohorts showed that patients with one compared with no exacerbation in the previous year had a more than twofold increased risk for experiencing an exacerbation in the next year [30,31]. Then again, the most recent study on triple therapy (KRONOS) was effective in reducing exacerbations even in symptomatic patients without history of exacerbation as the inclusion criterium (70\% of patients had no exacerbations in the previous year) [1]. Additional tools to predict exacerbation risk and treatment response and establish the risk/benefit ratio are needed. Eosinophil counts might help to fulfil this need [32]. This concept has been adopted by the most recent update of the GOLD strategy document, which has also introduced the criteria of $100-300$ blood eosinophils $\mu \mathrm{L}^{-1}$ for considering ICS and of $>300$ blood eosinophils $\mu \mathrm{L}^{-1}$ for recommending an ICS containing combination [3].

6) Even without any evidence, just as an expert opinion deriving from clinical practice, we believe that there are two other conditions where triple therapy may be considered as first choice and not as a step-up.

- First, in the patient discharged from the hospital after an acute exacerbation of COPD, and in whom COPD is diagnosed for the first time because of the severe exacerbation. These patients are commonly given the usual treatment with inhaled bronchodilators (mostly continuous short-acting $\beta_{2}$-agonists and short-acting muscarinic antagonists as nebulised therapy), systemic steroids and antibiotics during their hospitalisation, and are at high risk of re-hospitalisation particularly during the first month [33, 34]. We suggest that these rare cases could be put on maintenance therapy at least for the first 1-3 months and then narrowly considered for step-down (figure 1).

- Second, in patients who present for the first time, and are diagnosed with severe airway obstruction (forced expiratory volume in $1 \mathrm{~s}<50 \%$ ), are symptomatic, had frequent moderate $(\geqslant 2$ ) or severe exacerbations ( $\geqslant 1$ hospitalisation) in the previous year, and have peripheral eosinophilia $\left(>300 \mathrm{cells} \cdot \mu \mathrm{L}^{-1}\right)$, i.e. patients at high risk of recurrent exacerbations and/or hospitalisation [33, 35-37]. Also, for these patients we would recommend to put them on maintenance therapy with triple therapy at least for the first 3 months and then consider a step-down (figure 1).

\section{Patients with COPD not to treat with triple therapy}

1) All studies performed, to date, with triple therapy have included symptomatic patients, i.e.patients with either CAT $\geqslant 10$ and/or modified Medical Research Council $\geqslant 2$. We see no reason with the evidence available at this point to consider triple therapy for asymptomatic patients, unless the patient fulfils point 2,3 or 4 outlined in the previous section and has few symptoms in between exacerbations.

2) Similarly, even if symptomatic smokers with normal lung function or restrictive impairment may in fact have a similar risk of exacerbations as symptomatic smokers with obstructive impairment [10], we see no reason with the evidence available at this point to consider triple therapy for symptomatic patients without airflow limitation.

3) While the recent studies with triple therapy in a single inhaler suggest an effect on survival after 1 year of treatment $[25,38]$, this effect was observed only on a moderate to severe population of symptomatic patients at risk of exacerbations, and survival was not a predefined outcome Thus, until a properly designed study is performed and is positive on this outcome, triple therapy should not be considered to improve survival in COPD patients

4) The most recent triple therapy study included symptomatic COPD patients with moderate-to-very severe airflow limitation without a history of exacerbations in the previous year, had a duration of 6 months and was powered on lung function and no patient-related outcome (PRO) (e.g. exacerbation) [1]. Although the study showed superiority of triple over dual combinations not only on lung function but also on relevant secondary PROs (e.g. symptoms and exacerbations), without safety concerns, we usually need at least two consistent RCTs on a clinically relevant primary outcome before issuing recommendations. Thus, we believe that triple therapy should not be recommended as regular treatment for patients without a history of exacerbations in the previous year. 


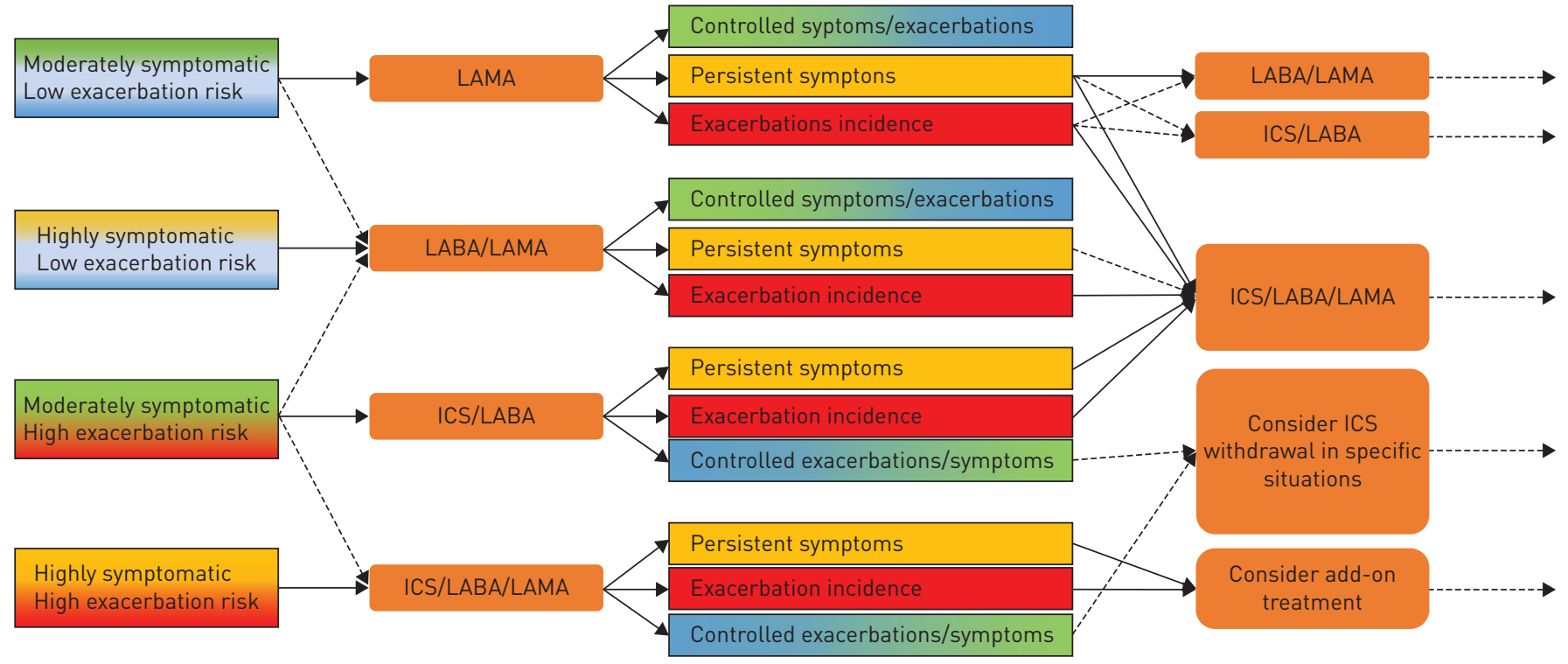

FIGURE 1 Schematic overview of the suggested pharmacological management of chronic obstructive pulmonary disease (COPD). We suggest an initial treatment for the patient as a function of the first presentation and correct COPD diagnosis. The majority of patients will not receive triple therapy at first presentation, but depending their natural history might end up escalating to triple therapy. Patients who present for the first time with hospitalisation or high symptoms and high exacerbation risk could be considered for triple therapy, which is then re-evaluated during follow up. LAMA: long-acting muscarinic antagonist; LABA: long-acting $\beta_{2}$-agonist; ICS: inhaled corticosteroid.

5) COPD and eosinopenia. There is evidence to suggest that the effect of ICS on COPD exacerbations increases with the number of circulating eosinophils, and that they are ineffective in patients with low blood eosinophils $\left(50-100\right.$ cells. $\left.\mu \mathrm{L}^{-1}[26,35,39]\right)$, and that eosinopenia increases the risk of pneumonia $[40,41]$. For these reasons, unless strictly necessary because either bronchodilators are not sufficient, or there is a history of active severe uncontrolled asthma, we would not recommend the use of ICS, including triple therapy, in patients with $<100$ eosinophils $\mu \mathrm{L}^{-1}$.

6) Patients with COPD are at increased risk of infections, particularly pneumonia, bronchiectasis, tuberculosis and even non-tuberculous mycobacterial infections [3]. Patients with COPD at risk of recurrent pneumonias with or without bronchiectasis, patients with bronchiectasis and recurrent respiratory infections, and patients with active tuberculosis should be not be treated with ICS, including triple therapy, and if ICS are strictly required, they should be carefully monitored for the risk of infection.

7) Patients with HIV treated with antiretroviral therapy (ARVs) often present with COPD [42], which is sometimes severe. ICS should not be co-administered in HIV patients on an ARV-boosted regimen due to the strong inhibition of their metabolism, which increases the risk of Cushing's syndrome, particularly fluticasone and budesonide. Only beclomethasone dipropionate may be considered, if strictly needed, but with careful monitoring of drug dosage or timing of administration [43].

8) Similarly, in clinical practice, we should be careful in considering individual or combined bronchodilator components (LABA and/or LAMA) or triple therapy in severe multimorbid COPD patients (particularly severe arrhythmias, severe heart failure and/or ischaemic heart disease, stroke, transient ischaemic attacks, etc.) in whom the efficacy/safety of these agents have not been tested [44-46].

\section{Conclusions}

Triple therapy should not be applied to most patients diagnosed with COPD as the majority have low symptoms and low exacerbation risk [47] and can be controlled with non-pharmacological interventions and bronchodilators only (figure 1). However, those who remain symptomatic even during maintenance treatment with bronchodilators or had a moderate-to-severe exacerbation in the previous year, persistent accelerated decline in lung function or those having a previous diagnosis of asthma or overlapping characteristics with asthma, might in our opinion be candidates for at least a trial with triple therapy, although this is not compliant with GOLD, EMA or FDA recommendations. By contrast, triple therapy should not be considered in asymptomatic subjects regardless of the degree of airflow limitation, in subjects without a correct diagnosis, or in subjects at high risk of complications linked to its components, particularly the ICS. 
We realise that some of our suggestions derive from clinical practice and are not supported by evidence, and thus that the effects to be expected are unknown and might be disproved by future studies. However, as often happens in medicine, we hope that our suggestions might be of some help for individual patients who do not meet the criteria recommended by the current documents [3].

Conflict of interest: L.E.G.W. Vanfleteren reports personal fees from AstraZeneca, Chiesi, Pulmonx, GlaxoSmithKline, and Novartis, outside the submitted work. A. Ullman reports grants from AstraZeneca and Novartis, grants and personal fees from GSK and Boehringer, personal fees from Chiesi, other from Verona Pharm (COPD product in phase II, board member), outside the submitted work. A. Nordenson reports personal fees from Chiesi, GlaxoSmithKline, Novartis, and Boehringer Ingelheim, outside the submitted work. A. Andersson reports personal fees from AstraZeneca, Novartis, and Teva, outside the submitted work. K. Andelid reports personal fees from GlaxoSmithKline, Novartis, and Boehringer Ingelheim, outside the submitted work. L.M. Fabbri reports personal fees and non-financial support from AstraZeneca, GSK, Novartis, Menarini, Boehringer Ingelheim, Zambon and Pearl Therapeutics, grants, personal fees and non-financial support from Chiesi, and non-financial support from Dompe, outside the submitted work.

\section{References}

1 Ferguson GT, Rabe KF, Martinez FJ, et al. Triple therapy with budesonide/glycopyrrolate/formoterol fumarate with co-suspension delivery technology versus dual therapies in chronic obstructive pulmonary disease (KRONOS): a double-blind, parallel-group, multicentre, phase 3 randomised controlled trial. Lancet Respir Med 2018; 6: 747-758.

2 Vestbo J, Papi A, Corradi M, et al. Single inhaler extrafine triple therapy versus long-acting muscarinic antagonist therapy for chronic obstructive pulmonary disease (TRINITY): a double-blind, parallel group, randomised controlled trial. Lancet 2017; 389: 1919-1929.

3 The Global Initiative for Chronic Obstructive Lung Disease (GOLD). 2019 Global Strategy for Prevention, Diagnosis and Management of COPD, 2018. www.goldcopd.org

4 Calverley PMA, Magnussen H, Miravitlles M, et al. Triple therapy in COPD: what we know and what we don't. COPD 2017; 14: 648-662.

5 Mantero M, Radovanovic D, Santus $\mathrm{P}$, et al. Management of severe COPD exacerbations: focus on beclomethasone dipropionate/formoterol/glycopyrronium bromide. Int J Chron Obstruct Pulmon Dis 2018; 13 2319-2333.

6 McDonald CF, Bardin PG. High or low impact? Triple therapy in chronic obstructive pulmonary disease. Respirology 2018; 23: 891-892.

7 Montuschi P, Malerba M, Macis G, et al. Triple inhaled therapy for chronic obstructive pulmonary disease. Drug Discov Today 2016; 21: 1820-1827.

8 Singh D. Single inhaler triple therapy with extrafine beclomethasone, formoterol, and glycopyrronium for the treatment of chronic obstructive pulmonary disease. Expert Opin Pharmacother 2018; 19: 1279-1287.

9 Singh D, Corradi M, Spinola M, et al. Triple therapy in COPD: new evidence with the extrafine fixed combination of beclomethasone dipropionate, formoterol fumarate, and glycopyrronium bromide. Int J Chron Obstruct Pulmon Dis 2017; 12: 2917-2928.

10 Woodruff PG, Barr RG, Bleecker E, et al. Clinical significance of symptoms in smokers with preserved pulmonary function. N Engl J Med 2016; 374: 1811-1821.

11 Brusselle G, Price D, Gruffydd-Jones K, et al. The inevitable drift to triple therapy in COPD: an analysis of prescribing pathways in the UK. Int J Chron Obstruct Pulmon Dis 2015; 10: 2207-2217.

12 Pauwels RA, Lofdahl CG, Laitinen LA, et al. Long-term treatment with inhaled budesonide in persons with mild chronic obstructive pulmonary disease who continue smoking. European Respiratory Society Study on Chronic Obstructive Pulmonary Disease. N Engl J Med 1999; 340: 1948-1953.

13 Vestbo J, Sorensen T, Lange P, et al. Long-term effect of inhaled budesonide in mild and moderate chronic obstructive pulmonary disease: a randomised controlled trial. Lancet 1999; 353: 1819-1823.

14 Burge PS, Calverley PM, Jones PW, et al. Randomised, double blind, placebo controlled study of fluticasone propionate in patients with moderate to severe chronic obstructive pulmonary disease: the ISOLDE trial. $B M J$ 2000; 320: 1297-1303.

15 Wise R, Connett J, Weinmann G, et al. Effect of inhaled triamcinolone on the decline in pulmonary function in chronic obstructive pulmonary disease. N Engl J Med 2000; 343: 1902-1909.

16 Tashkin DP, Celli B, Decramer M, et al. Bronchodilator responsiveness in patients with COPD. Eur Respir J 2008; 31: 742-750.

17 Decramer M, Celli B, Kesten S, et al. Effect of tiotropium on outcomes in patients with moderate chronic obstructive pulmonary disease (UPLIFT): a prespecified subgroup analysis of a randomised controlled trial. Lancet 2009; 374: 1171-1178.

18 Vestbo J, Anderson JA, Brook RD, et al. Fluticasone furoate and vilanterol and survival in chronic obstructive pulmonary disease with heightened cardiovascular risk (SUMMIT): a double-blind randomised controlled trial Lancet 2016; 387: 1817-1826.

19 Calverley PMA, Anderson JA, Brook RD, et al. Fluticasone furoate, vilanterol, and lung function decline in patients with moderate chronic obstructive pulmonary disease and heightened cardiovascular risk. Am J Respir Crit Care Med 2018; 197: 47-55.

20 Magnussen H, Disse B, Rodriguez-Roisin R, et al. Withdrawal of inhaled glucocorticoids and exacerbations of COPD. N Engl J Med 2014; 371: 1285-1294.

21 Naya I, Compton C, Ismaila AS, et al. Preventing clinically important deterioration with single-inhaler triple therapy in COPD. ERJ Open Res 2018; 4: 00047-2018.

22 Lange P, Colak Y, Ingebrigtsen TS, et al. Long-term prognosis of asthma, chronic obstructive pulmonary disease, and asthma-chronic obstructive pulmonary disease overlap in the Copenhagen City Heart study: a prospective population-based analysis. Lancet Respir Med 2016; 4: 454-462. 
23 Papi A, Vestbo J, Fabbri L, et al. Extrafine inhaled triple therapy versus dual bronchodilator therapy in chronic obstructive pulmonary disease (TRIBUTE): a double-blind, parallel group, randomised controlled trial. Lancet 2018; 391: 1076-1084.

24 Singh D, Papi A, Corradi M, et al. Single inhaler triple therapy versus inhaled corticosteroid plus long-acting beta2-agonist therapy for chronic obstructive pulmonary disease (TRILOGY): a double-blind, parallel group, randomised controlled trial. Lancet 2016; 388: 963-973.

25 Lipson DA, Barnhart F, Brealey N, et al. Once-daily single-inhaler triple versus dual therapy in patients with COPD. N Engl J Med 2018; 378: 1671-1680.

26 Lipson DA, Barnacle H, Birk R, et al. FULFIL trial: once-daily triple therapy for patients with chronic obstructive pulmonary disease. Am J Respir Crit Care Med 2017; 196: 438-446.

27 Postma DS, Rabe KF. The asthma-COPD overlap syndrome. N Engl J Med 2015; 373: 1241-1249.

28 GINA. 2018 GINA Report, Global strategy for asthma management and prevention. 2018. ginasthma.org

29 Fabbri LM, Roversi S, Beghe B. Triple therapy for symptomatic patients with COPD. Lancet 2017; 389: 1864-1865.

30 Han MK, Quibrera PM, Carretta EE, et al. Frequency of exacerbations in patients with chronic obstructive pulmonary disease: an analysis of the SPIROMICS cohort. Lancet Respir Med 2017; 5: 619-626.

31 Hurst JR, Vestbo J, Anzueto A, et al. Susceptibility to exacerbation in chronic obstructive pulmonary disease. N Engl J Med 2010; 363: 1128-1138.

32 Pascoe S, Locantore N, Dransfield MT, et al. Blood eosinophil counts, exacerbations, and response to the addition of inhaled fluticasone furoate to vilanterol in patients with chronic obstructive pulmonary disease: a secondary analysis of data from two parallel randomised controlled trials. Lancet Respir Med 2015; 3: 435-442.

33 Rothnie KJ, Mullerova H, Smeeth L, et al. Natural history of chronic obstructive pulmonary disease exacerbations in a general practice-based population with chronic obstructive pulmonary disease. Am J Respir Crit Care Med 2018; 198: 464-471.

34 Lindenauer PK, Dharmarajan K, Qin L, et al. Risk trajectories of readmission and death in the first year after hospitalization for chronic obstructive pulmonary disease. Am J Respir Crit Care Med 2018; 197: 1009-1017.

35 Bafadhel M, Pavord ID, Russell REK. Eosinophils in COPD: just another biomarker? Lancet Respir Med 2017; 5: 747-759.

36 Calverley PMA, Tetzlaff K, Vogelmeier C, et al. Eosinophilia, frequent exacerbations, and steroid response in chronic obstructive pulmonary disease. Am J Respir Crit Care Med 2017; 196: 1219-1221.

37 Rabe KF, Calverley PMA, Martinez FJ, et al. Effect of roflumilast in patients with severe COPD and a history of hospitalisation. Eur Respir J 2017; 50: 1700158.

38 Vestbo J, Fabbri L, Papi A, et al. Inhaled corticosteroid containing combinations and mortality in COPD Eur Respir J 2018; 52: 1801230.

39 Pascoe S, Locantore N, Dransfield MT, et al. Blood eosinophil counts, exacerbations, and response to the addition of inhaled fluticasone furoate to vilanterol in patients with chronic obstructive pulmonary disease: a secondary analysis of data from two parallel randomised controlled trials. Lancet Respir Med 2015; 3: 435-442.

40 Ernst P. Blood eosinophils in COPD and the future risk of pneumonia. Eur Respir J 2018; 52: 1800981.

41 Pavord ID, Lettis S, Anzueto A, et al. Blood eosinophil count and pneumonia risk in patients with chronic obstructive pulmonary disease: a patient-level meta-analysis. Lancet Respir Med 2016; 4: 731-741.

42 Bigna JJ, Kenne AM, Asangbeh SL, et al. Prevalence of chronic obstructive pulmonary disease in the global population with HIV: a systematic review and meta-analysis. Lancet Glob Health 2018; 6: e193-e202.

43 Elliot ER, Theodoraki A, Jain LR, et al. Iatrogenic Cushing's syndrome due to drug interaction between glucocorticoids and the ritonavir or cobicistat containing HIV therapies. Clin Med (Lond) 2016; 16: 412-418.

44 Suissa S, Dell'Aniello S, Ernst P. Concurrent use of long-acting bronchodilators in COPD and the risk of adverse cardiovascular events. Eur Respir J 2017; 49: 1602245.

45 Rogliani P, Matera MG, Ora J, et al. The impact of dual bronchodilation on cardiovascular serious adverse events and mortality in COPD: a quantitative synthesis. Int J Chron Obstruct Pulmon Dis 2017; 12: 3469-3485.

46 Wang MT, Tsai CL, Lo YW, et al. Risk of stroke associated with inhaled ipratropium bromide in chronic obstructive pulmonary disease: a population-based nested case-control study. Int J Cardiol 2012; 158: 279-284.

47 Cabrera Lopez C, Casanova Macario C, Marin Trigo JM, et al. Comparison of the 2017 and 2015 Global Initiative for Chronic Obstructive Lung Disease Reports. Impact on Grouping and Outcomes. Am J Respir Crit Care Med 2018; 197: 463-469. 